\title{
Review
}

\section{Lessons from Epidemiologic Research about Risk Factors, Modifiers, and Progression of Late Onset Alzheimer's Disease in New York City at Columbia University Medical Center}

\author{
Devangere Devanand ${ }^{\mathrm{a}, \mathrm{b}}$, Joseph Lee ${ }^{\mathrm{c}, \mathrm{d}, \mathrm{e}}$, Jose Luchsinger ${ }^{\mathrm{e}, \mathrm{f}, *}$, Jennifer Manly ${ }^{\mathrm{c}, \mathrm{d}, \mathrm{g}}$, Karen Marder ${ }^{\mathrm{d}, \mathrm{g}}$, \\ Richard Mayeux ${ }^{\mathrm{a}, \mathrm{c}, \mathrm{d}, \mathrm{e}, \mathrm{g}}$, Nikolaos Scarmeas ${ }^{\mathrm{c}, \mathrm{d}, \mathrm{g}}$, Nicole Schupf ${ }^{\mathrm{c}, \mathrm{d}, \mathrm{e}}$ and Yaakov Stern ${ }^{\mathrm{c}, \mathrm{d}, \mathrm{g}}$ \\ ${ }^{a}$ Department of Psychiatry, Columbia University Medical Center, New York, NY, USA \\ ${ }^{\mathrm{b}}$ Division of Geriatric Psychiatry, New York State Psychiatric Institute, New York, NY, USA \\ ${ }^{\mathrm{c}}$ Gertrude H. Sergievsky Center, New York, NY, USA \\ ${ }^{\mathrm{d}}$ Taub Institute for Research on Alzheimer's Disease and the Aging Brain, New York, NY, USA \\ ${ }^{\mathrm{e}}$ Department of Epidemiology, Joseph P. Mailman School of Public Health, Columbia University Medical Center, \\ New York, NY, USA \\ ${ }^{\mathrm{f}}$ Department of Medicine, Columbia University Medical Center, New York, NY, USA \\ ${ }^{\mathrm{g}}$ Department of Neurology, Columbia University Medical Center, New York, NY, USA
}

\begin{abstract}
This review summarizes the findings and importance of 12 articles from research at Columbia University in New York City that were among the most cited in the literature between 2006 and 2011. The 12 articles summarized in this review made important contributions to the field of Alzheimer's disease in the last 5 years. Four of the articles established the Mediterranean diet as a food consumption pattern that may prevent Alzheimer's disease in addition to physical activity. Two of the articles advanced our knowledge of predictors of conversion from mild cognitive impairment to dementia. Four of the articles provided important knowledge of risk factors for the progression of Alzheimer's disease and its complications. Lastly, one of the articles laid the theoretical framework for the study of cognitive reserve, an important modifier of the manifestation of Alzheimer's disease. These studies have advanced our knowledge about risk factors, modifiers, and progression of late onset Alzheimer's disease.
\end{abstract}

Keywords: Alzheimer's disease, conversion, diet, cognitive reserve, epidemiology, genes, mild cognitive impairment, predictors, progression, risk factors

\footnotetext{
${ }^{*}$ Correspondence to: Jose A. Luchsinger, MD, MPH, Columbia University Medical Center, PH9 Center, room 210, 630 West 168th Street, New York, NY 10032, USA. Tel.: +1 212 3054730; E-mail: ja194@columbia.edu.
}

This review summarizes the findings and importance of 12 articles [1-12] from research at Columbia University in New York City that were among the most cited in the literature between 2006 and 2011. The determination of citations was made using the 
Thomson Reuters Bibliometric analysis tool called HistCite by Aaron Sorensen, Editor of the Journal of Alzheimer's Disease.

These studies come from three different cohorts based at Columbia University Medical Center in New York City. These cohorts are:

- The Washington Heights-Inwood Columbia Aging Project (WHICAP; PI: Richard Mayeux) is comprised of two related community-based cohorts, one recruited from 1992 to 1994 [13], and one recruited from 1999 to 2001 [14]. Subjects in WHICAP were 65 years and older at the time of recruitment, were enrolled in Medicare, and were from three ethnic groups: Hispanics, nonHispanic Blacks, and non-Hispanic Whites. The main goal of WHICAP is to study the epidemiology and predictors of cognitive disorders in an urban multiethnic cohort.

- The Predictors Study (PI: Yaakov Stern) is a community based cohort study of persons with a diagnosis of Alzheimer's disease (AD) followed prospectively. The main goal of the predictors study is to characterize the progression of $\mathrm{AD}$ and identify modifiers of progression.

- The Questionable Dementia 1 study (QD1; PI: Devangere Devanand), a cohort study of persons with a diagnosis of mild cognitive impairment (MCI), recruited from a referral memory disorders clinic. The goal of the QD1 study is to identify predictors of progression to dementia among persons with MCI.

Among the 12 most cited articles that resulted from these studies, four reported on modifiable risk factors for AD [1-4], one reported on genetic risk factors for $\mathrm{AD}$ [10], two reported on predictors of conversion of MCI to AD [7, 9], four reported on progression of $\mathrm{AD}[5,6,11,12]$, and one was a review article on an important modifier of AD risk, cognitive reserve [8]. This article is organized following these themes. We provide summaries of each article, put the findings in perspective, and briefly discuss their importance to the field.

\section{STUDIES OF NON-GENETIC RISK FACTORS FOR LATE ONSET ALZHEIMER'S DISEASE}

Four of the 12 studies examined the relationship of putative risk factors with incident AD [1-4]. These studies are summarized in Table 1 . These studies were conducted in WHICAP. All of the studies examined diet, and more specifically, adherence to the Mediterranean diet, in relation to incident $\mathrm{AD}$ or MCI. One of the studies also examined physical activity in addition to diet [4]. One of the studies examined the role of vascular mediation in the relationship of the Mediterranean diet with $\mathrm{AD}$ [4]. In summary, these studies found that higher adherence to a Mediterranean diet was related to a lower risk of MCI and AD, that these relationships were not explained by vascular mediation, and were stronger when accompanied with higher physical activity. In relation to the lack of mediation by vascular disease, it is likely that this finding was explained by the lack of sensitivity of medical history and blood markers as surrogates for cerebrovascular disease. We later found that cerebrovascular disease ascertained on brain imaging did suggest a vascular mediation in this relationship [15].

This compendium of articles is important for several reasons. First, no modifiable risk factors for AD have been identified thus far despite intensive research [16], and these studies demonstrate that lifestyle factors with available evidence for benefits for cardiovascular disease can also help AD potentially through nonvascular mechanisms. Second, the study of diet and AD had traditionally been limited to the study of specific nutrients (e.g., vitamins) rather than food consumption patterns. Our studies were the first to examine how an established measurable food consumption pattern, the Mediterranean diet, could reduce the risk of AD. Third, one of the studies demonstrated that adhering to two available healthy life-style choices, the Mediterranean diet and physical activity, could jointly decrease the risk of AD. It is important to point out that these studies carefully accounted for confounders such as caloric intake and low education. Thus, we do not believe that these important findings are explained by confounding factors.

\section{STUDIES OF GENETIC RISK FACTORS FOR LATE ONSET ALZHEIMER'S DISEASE}

One of the 12 studies examined the relationship of a novel genetic risk factor, SORL1, with AD [10]. Variants in $3^{\prime}$ and $5^{\prime}$ regions of SORL1, the neuronal sorting protein-related receptor, have been found to be associated with late onset familial and sporadic AD in several datasets that were selected for familial aggregation or were ethnically diverse or clinic-based selected series. Our nested case-control study was performed using 


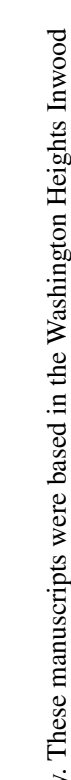

||W

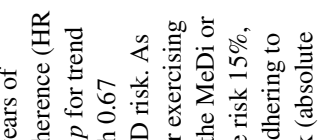

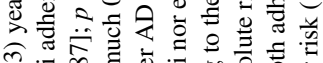

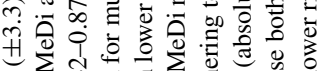

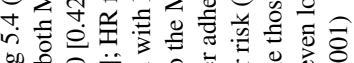

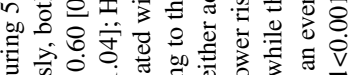

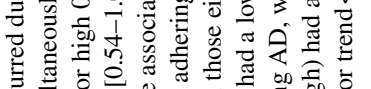

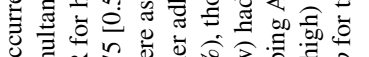

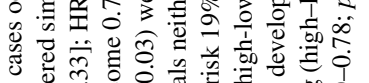

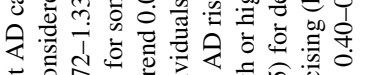

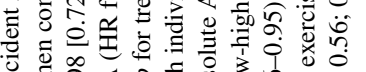

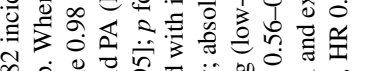

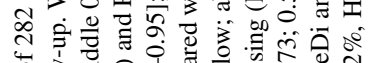

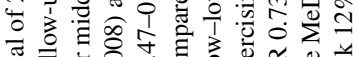

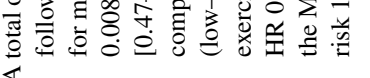

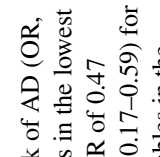

药

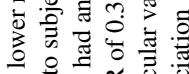

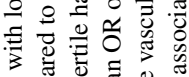

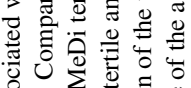

范客吾

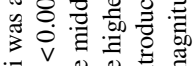

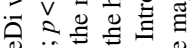

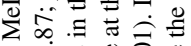

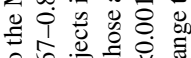

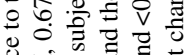

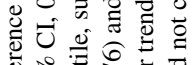

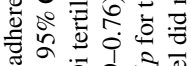

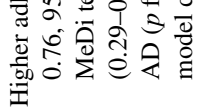

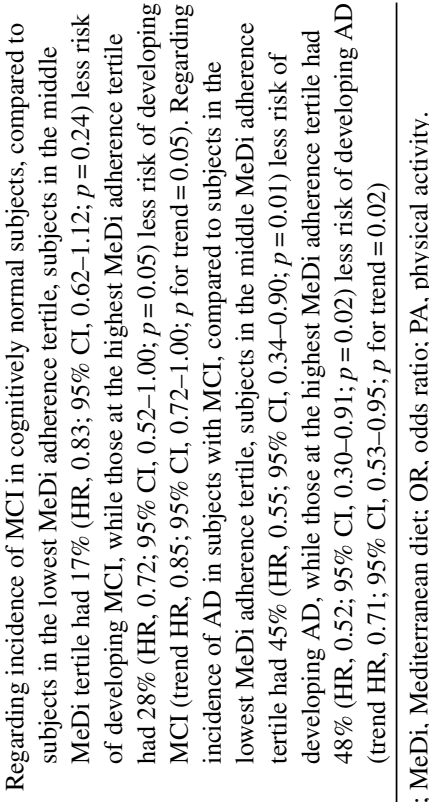

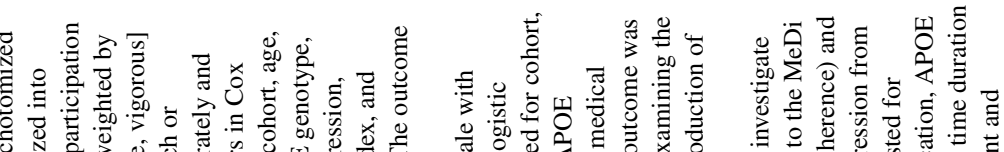

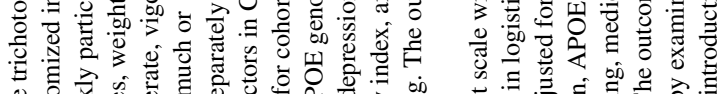

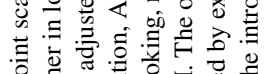

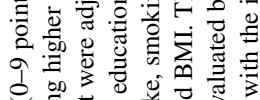

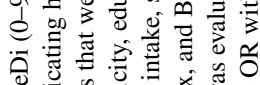

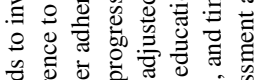

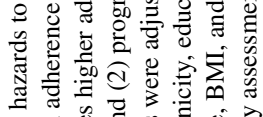

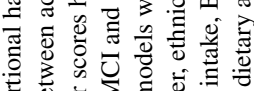

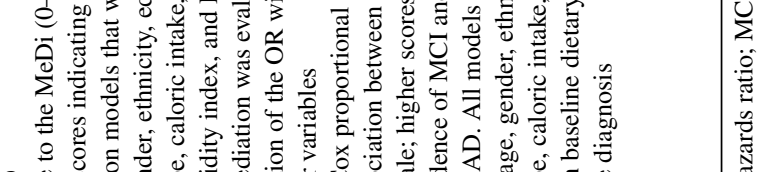

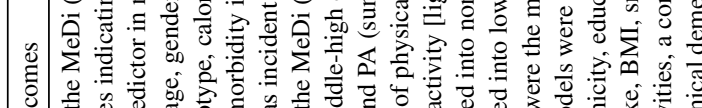

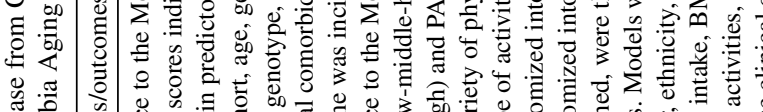
安

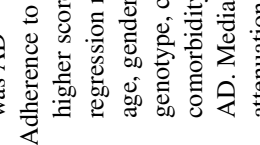

$\begin{array}{ll} & \\ 0 & \end{array}$
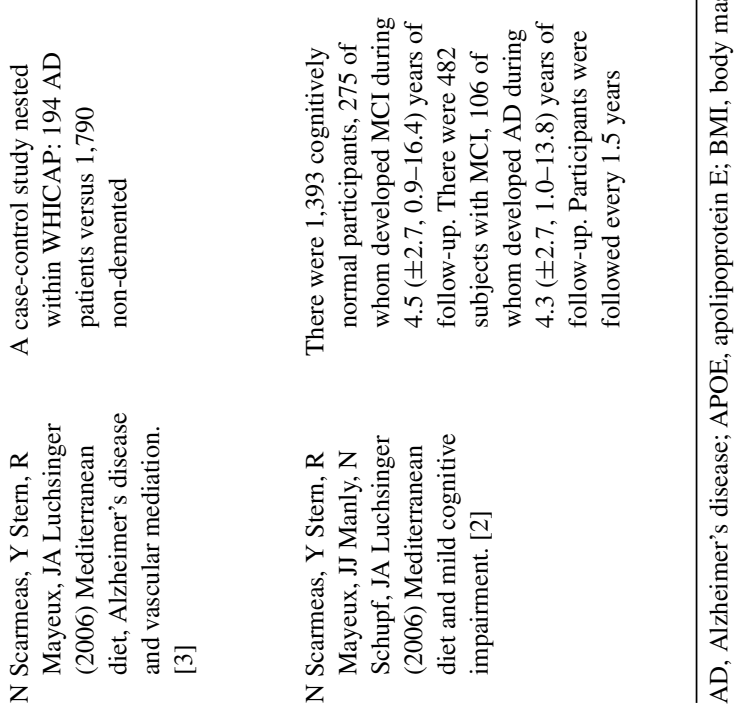
the community-based WHICAP study. There were 296 patients with probable AD and 428 healthy elderly controls. The participants were of African American (34\%), Caribbean Hispanic (51\%), or non-Hispanic whites (15\%). Several individual single-nucleotide polymorphisms (SNPs) and SNP haplotypes were significantly associated with $\mathrm{AD}$ in this prospectively collected community-based cohort, confirming the previously reported positive association of SORL1 with AD. SNP 12 near the $5^{\prime}$ region was associated with AD in African-Americans and Hispanics. Two SNPs in the $3^{\prime}$ region were also associated with $\mathrm{AD}$ in African-Americans (SNP 26) and whites (SNP 20). A single haplotype C-C-A at SNPs 4-6 was associated with $\mathrm{AD}$ in Hispanics. However, several different haplotypes were associated with $\mathrm{AD}$ in the AfricanAmericans and whites, including the haplotype T-T-C at SNPs 23-25 ( $p=0.035)$ that was significantly associated with $\mathrm{AD}$ in the North European whites in a previous report.

The contributions of this article to the field included the confirmation of the association between $\mathrm{AD}$ and variants in the SORL1 gene in a population based multiethnic cohort. Also, the discovery of significant association in multiple regions of the gene, and the discovery of different AD-associated haplotypes different from those in other studies revealed that there may be a high degree of allelic heterogeneity, with disease-associated variants occurring on multiple different haplotypic backgrounds. Thus, second attempts to identify the pathogenic variants in SORL1 will likely have to investigate larger regions of the SORL1 gene than simply just between SNPs 8-10 and 22-25. This study is part of a larger effort in genetic epidemiology research in which our group participates that has established SORL-1 as one the most important genetic risk factors for $\mathrm{AD}$ [17-21] after APOE- 84 . Late onset $\mathrm{AD}$ is increasing recognized as a complex heterogeneous condition in which multiple pathways and factors are likely to be involved. The discovery of new genetic factors in late onset $\mathrm{AD}$, in this case SORL-1, is providing new insights into these pathways.

\section{STUDIES OF CONVERSION FROM MILD COGNITIVE IMPAIRMENT TO ALZHEIMER'S DISEASE}

Two of the 12 articles [7, 9] (Table 2) summarized in this review reported neuropsychological and imaging predictors of conversion from non-dementia cognitive impairment to AD in the QD1 study. QD1 was a cohort based in a memory disorders clinic, as compared with the studies of non-genetic and genetic risk factors previously described, which were community-based.

The first article [7] evaluated conversion rates to $\mathrm{AD}$ in subtypes of MCI and identified neuropsychological measures most predictive of the time to conversion. This study demonstrated that mildly cognitively impaired patients with memory plus other cognitive domain deficits, rather than those with pure amnestic MCI, constituted the high risk group for conversion. Deficits in verbal memory and psychomotor speed/executive function abilities strongly predicted conversion to AD. This study raised the intriguing possibility that these amnestic "plus" patients constitute a group at high risk for conversion to $\mathrm{AD}$, whereas the pure amnestic MCI patients may not be at such a high risk. However, with longer follow-up, the pure amnestic MCI patients may develop multiple cognitive domain deficits and eventually convert to AD. These findings also suggest that testing for deficits in multiple cognitive domains in addition to those in memory improves the predictive value of neuropsychological testing in patients with MCI. The study showed that combining commonly used neuropsychological tests strongly predicted conversion from MCI to $\mathrm{AD}$, emphasizing the critical role of cognitive testing in evaluation and prediction of outcome in patients with MCI.

The second article [9] evaluated the utility of magnetic resonance imaging (MRI) hippocampal and entorhinal cortex size in predicting conversion from MCI to AD. Hippocampal and entorhinal cortex volumes were each largest in controls, intermediate in MCI non-converters, and smallest in MCI converters to AD. Smaller hippocampal volume and entorhinal cortex volume each predicted time to conversion to AD. Similar results were obtained for hippocampal and entorhinal cortex volume in patients with MCI with Mini-Mental State Exam (MMSE) scores $\geq 27 / 30$ ( $21 \%$ converted to AD) and in the subset of patients with amnestic MCI (35\% converted to AD). In the total patient sample, when both hippocampal and entorhinal volume were entered into an age-stratified Cox model with gender, MMSE, education, and intracranial volume, smaller hippocampal volume and entorhinal cortex volume predicted time to conversion to $\mathrm{AD}$. Similar results were obtained in a Cox model that also included neuropsychological test scores. Based on logistic regression models in the 3-year follow-up sample, for a fixed specificity of $80 \%$, the addition of hippocampal and entorhinal cortex volumes to 


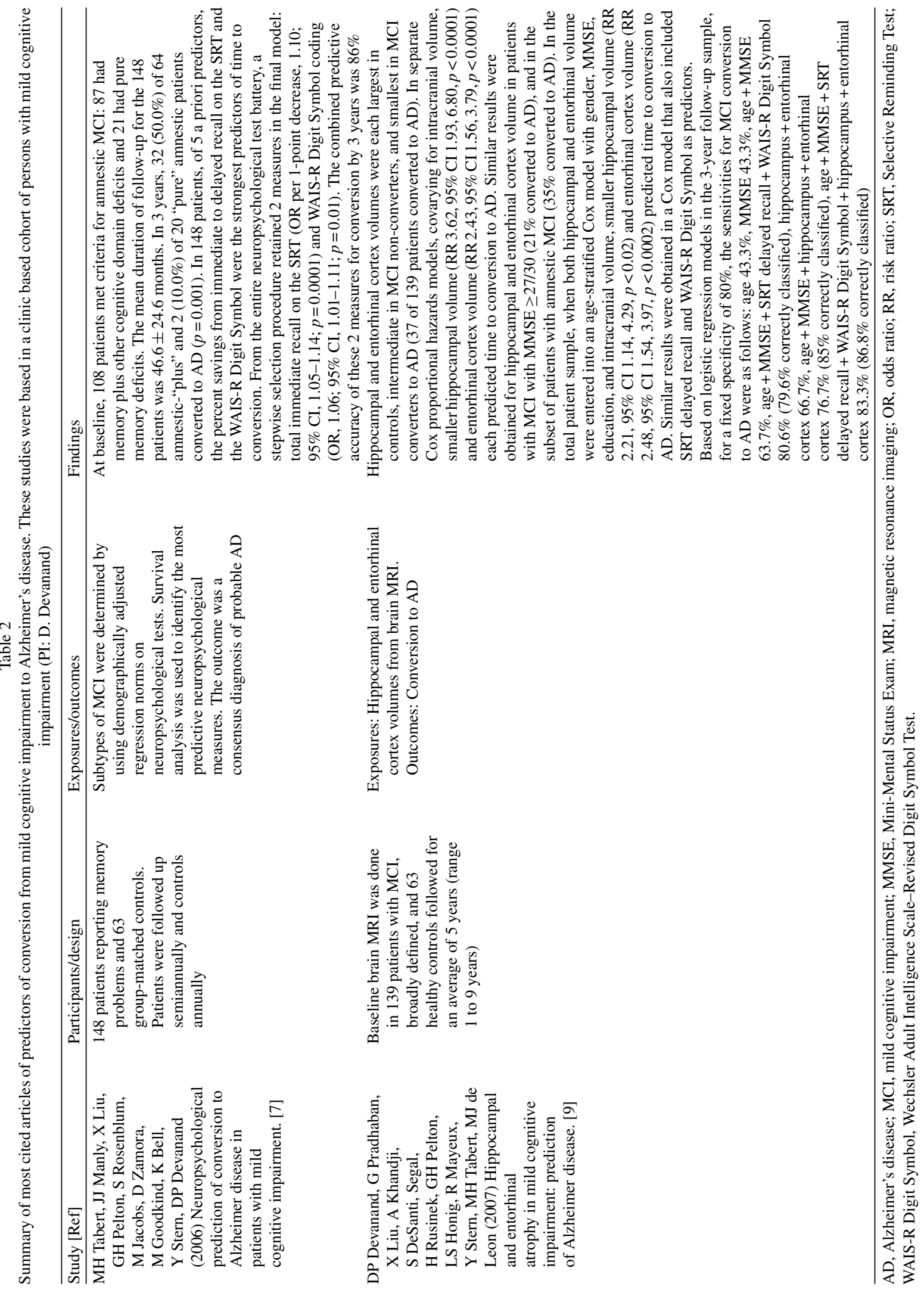


Table 3

Summary of most cited articles reporting on the progression of late onset Alzheimer's disease. The studies are based in a cohort of persons with late onset Alzheimer's disease in New York City (PI: Y. Stern)

\begin{tabular}{lll}
\hline Study [Ref] & Participants/design & Exposures/outcomes \\
\hline N Scarmeas, SM Albert, & During the course of a & The subjects received an average of \\
JJ Manly, Y Stern & community-based & 3.7 (up to 9) neuropsychological \\
(2006) Education and & multiethnic prospective & assessments consisting of 12 \\
rates of cognitive & cohort study of & individual tests. With the aid of a \\
decline in incident & individuals aged $\geq 65$ & normative sample, a standardized \\
Alzheimer's disease. & years living in New & composite cognitive score, as well \\
[5] & York, 312 patients were & as individual cognitive domain \\
& diagnosed with & scores were calculated. GEE \\
& incident AD and were & models were used to examine the \\
& followed overall for 5.6 & association between education and \\
(up to 13.3) years & rates of cognitive decline
\end{tabular}

\author{
N Scarmeas, JA \\ Luchsinger, R Mayeux, \\ Y Stern (2007) \\ Mediterranean diet and \\ Alzheimer's disease \\ mortality. [12]
}

\section{A total of 192 \\ community-based individuals in New York who were diagnosed with $\mathrm{AD}$ were prospectively followed every 1.5 \\ years}

Adherence to the MeDi (0-9 point scale with higher scores indicating higher adherence) was the main predictor of mortality in Cox models that were adjusted for period of recruitment, age, gender, ethnicity, education, APOE genotype, caloric intake, smoking, and BMI

\footnotetext{
JC Amatniek, WA

Hauser, C

DelCastillo-Castaneda,

DM Jacobs, K Marder,

K Bell, M Albert, J

Brandt, Y Stern (2006)

Incidence and

predictors of seizures

in patients with

Alzheimer's disease.

[11]
}

Findings

Composite cognitive performance declined by $9 \%$ of a standard deviation per year. Rates of decline before and after $\mathrm{AD}$ incidence were similar. For each additional year of education there was $0.3 \%$ standard deviation lower composite cognitive performance for each year of follow-up. The association between higher education and faster decline was noted primarily in the executive-speed $(0.6 \%)$ and memory $(0.5 \%)$ cognitive domains and was present over and above age, gender, ethnicity, differential baseline cognitive performance, depression, and vascular comorbidity

85 AD patients (44\%) died during the course of $4.4( \pm 3.6,0.2-13.6)$ years of follow-up. In unadjusted models, higher adherence to MeDi was associated with lower mortality risk (for each additional MeDi point HR 0.79 ; 95\% CI 0.69-0.91; $p=0.001)$. This result remained significant after controlling for all covariates $(0.76$; [0.65-0.89]; $p=0.001)$. In adjusted models, as compared to $\mathrm{AD}$ patients at the lowest MeDi adherence tertile, those at the middle tertile had lower mortality risk $(0.65$; [0.38-1.09]; 1.33 years longer survival), while subjects at the highest tertile had an even lower risk (0.27 [0.10-0.69]; 3.91 years longer survival; $p$ for trend 0.003)

Mild AD patients were prospectively followed at 6-month intervals
Estimate incidence of unprovoked seizures, compare age-specific risk of unprovoked seizures with population norms, and identify characteristics at baseline (demographics, duration and severity of $\mathrm{AD}$, physical and diagnostic test findings, and comorbid medical and psychiatric conditions) influencing unprovoked seizure risk. Review of study charts and medical records supplemented coded end-point data
The cumulative incidence of unprovoked seizures at 7 years was nearly $8 \%$. In all age groups, risk was increased compared with a standard population, with an 87-fold increase in the youngest group (age 50-59 years) and more than a threefold increase in the oldest group (age $85+$ years). In multivariate modeling, independent predictors of unprovoked seizures were younger age (RR, 0.89 per year increase in age; $95 \% \mathrm{CI}$, 0.82-0.97), African-American ethnic background (RR, 7.35; $95 \%$ CI, 1.42-37.98), more-severe dementia (RR, 4.15; 95\% CI, 1.06-16.27), and focal epileptiform findings on EEG (RR, 73.36; $95 \%$ CI, 1.75-3075.25) 
Table 3

(Continued)

\begin{tabular}{|c|c|c|c|}
\hline Study [Ref] & Participants/design & Exposures/outcomes & Findings \\
\hline $\begin{array}{l}\text { EP Helzner, JA } \\
\text { Luchsinger, N } \\
\text { Scarmeas, S Cosentino, } \\
\text { AM Brickman, MM } \\
\text { Glymour, Y Stern } \\
\text { (2009) Contribution of } \\
\text { vascular risk factors to } \\
\text { disease progression in } \\
\text { Alzheimer's disease. } \\
\text { [6] }\end{array}$ & $\begin{array}{l}156 \text { incident } \mathrm{AD} \text { patients } \\
\text { (mean age } 83 \text { years at } \\
\text { diagnosis) were } \\
\text { prospectively followed } \\
\text { every } 1.5 \text { years }\end{array}$ & $\begin{array}{l}\text { The exposures were vascular factors } \\
\text { including medical history (heart } \\
\text { disease, stroke, diabetes, } \\
\text { hypertension), smoking, and } \\
\text { pre-diagnosis blood lipid } \\
\text { measurements (total cholesterol, } \\
\text { HDL-C, LDL-C, and } \\
\text { triglycerides). The main outcome } \\
\text { was change in a composite score of } \\
\text { cognitive ability from diagnosis on }\end{array}$ & $\begin{array}{l}\text { In GEE models (adjusted for age, } \\
\text { race/ethnicity and education), } \\
\text { higher cholesterol (total and } \\
\text { LDL-C), and diabetes history were } \\
\text { associated with faster cognitive } \\
\text { decline. Each } 10 \text {-unit increase in } \\
\text { cholesterol and LDL-C was } \\
\text { associated with a } 10 \% \text { of a standard } \\
\text { deviation decrease in cognitive } \\
\text { score per year of follow-up } \\
\text { ( } p<0.001 \text { for total cholesterol, } \\
p=0.001 \text { for LDL-C). HDL and } \\
\text { triglycerides were not associated } \\
\text { with rate of decline. Diabetes } \\
\text { history was associated with an } \\
\text { additional } 50 \% \text { of a standard } \\
\text { deviation decrease in cognitive } \\
\text { score per year ( } p=0.05 \text { ). History of } \\
\text { heart disease and stroke were } \\
\text { associated with cognitive decline } \\
\text { among APOE } \varepsilon 4 \text { carriers only. In a } \\
\text { final GEE model that included } \\
\text { HDL-C, LDL-C, and diabetes, only } \\
\text { higher LDL-C was independently } \\
\text { associated with faster cognitive } \\
\text { decline }\end{array}$ \\
\hline
\end{tabular}

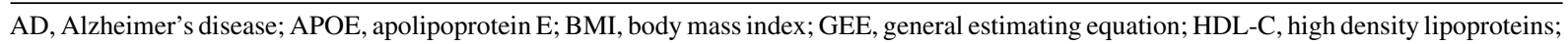
HR, hazards ratio; LDL-C, low density lipoproteins; MeDi, Mediterranean diet; RR, risk ratio.

demographic and neuropsychological variables markedly improved the sensitivity of a predictive model for conversion to AD to well over $80 \%$.

At the time that these two studies were published, they were the largest studies testing the predictors of conversion from MCI to AD. The study of neuropsychological predictors demonstrated that persons with amnestic MCI and involvement with other cognitive domains represented a higher risk group for conversion than those with pure amnestic MCI. The imaging study demonstrated that hippocampal and entorrinal cortex size add information to the neuropsychological data in predicting conversion from MCI to dementia. The importance of these studies in the field is that it helps clinicians identify persons with MCI at high risk for conversion. This group perhaps should be targeted for interventions.

\section{STUDIES OF PROGRESSION IN ALZHEIMER'S DISEASE}

Four of the 12 studies examined the predictors of progression and consequences of $\mathrm{AD}[6,11,12]$ (Table 3). Compared to the previous categories of studies, these studies were conducted in a cohort of persons with AD from Northern Manhattan followed prospectively. One study examined the association of years of education on $\mathrm{AD}$ progression and found that higher years of education were related to steeper cognitive decline [5]. Another study examined the association of vascular risk factors status before AD diagnosis with rate of cognitive decline and found that higher total cholesterol, low-density-lipoprotein cholesterol, and diabetes were associated with faster cognitive decline [6]. One study examined the association of Mediterranean diet adherence before AD diagnosis with mortality among persons with $\mathrm{AD}$ [12] and found that persons with higher Mediterranean diet adherence had lower mortality. Lastly, one study found that the incidence of seizures was higher than expected in persons with AD and that younger individuals, African Americans, and those with more severe disease or a focal epileptiform findings on EEG were more likely to have unprovoked seizures [12].

These studies are important because the prevalence of AD will continue to increase in the absence of established methods for prevention and cure, and because studying disease progression in AD provides insights about its mechanisms. The studies examining the roles of diet and vascular risk factors established that these 
exposures not only potentially affect the risk of $\mathrm{AD}$ but also its course and mortality. The study examining seizures shows clinicians following persons with AD that they should expect the need to treat seizures and provided potential predictors for this complication. The study on education and AD course provides important support for the cognitive reserve hypothesis that is discussed next.

\section{COGNITIVE RESERVE AND ALZHEIMER'S DISEASE}

This article was the only one out of the 12 to review a topic in AD [8] suggesting a framework for the study of an important hypothesized modifier of its clinical presentation. Epidemiologic evidence suggests that individuals with higher intelligence quotient, education, occupational attainment, or participation in leisure activities have a reduced risk of developing AD. The concept of cognitive reserve posits that individual differences in how tasks are processed provide differential reserve against brain pathology or age-related changes. This may take two forms, neural reserve and neural compensation. In neural reserve, pre-existing brain networks that are more efficient or have greater capacity may be less susceptible to disruption. In neural compensation, alternate networks may compensate for pathology's disruption of pre-existing networks. Imaging studies have begun to identify the neural substrate of cognitive reserve. Because cognitive reserve may modulate the clinical expression of AD pathology, it is an important consideration in studies of "preclinical" $\mathrm{AD}$ and treatment studies. There is also the possibility that directly enhancing cognitive reserve may help forestall the diagnosis of AD.

The AD field is at a juncture in which there is growing acceptance that this disease is more heterogeneous than originally thought and there is uncertainty about the validity of the hypothesis that postulates that brain amyloid deposition is the main culprit. Other aspects such as vascular disease are increasingly recognized as contributors to $\mathrm{AD}$, but even this element has proven insufficient to explain AD risk. In this context, the concept of cognitive reserve has emerged as an important modifier of disease expression that requires further study. Research is needed to better characterize the measurement of this concept and to understand how it affects AD risk. For example, a sensitive measure of cognitive reserve could help the assessment of its modulation of risk factors such as the Mediterranean diet, could improve predictive models for conversion from $\mathrm{MCI}$ to $\mathrm{AD}$, and could help better predict to progression of $\mathrm{AD}$.

\section{SUMMARY}

The 12 articles summarized in this review made important contributions to the field of $\mathrm{AD}$ in the last 5 years. Four of the articles established the Mediterranean diet as a food consumption pattern that may prevent $\mathrm{AD}$ in addition to physical activity. Two of the articles advanced our knowledge of predictors of conversion from MCI to dementia. Four of the articles provided important knowledge of risk factors for the progression of $\mathrm{AD}$ and its complications. Lastly, one of the articles laid the theoretical framework for the study of cognitive reserve, an important modifier of the manifestation of $\mathrm{AD}$.

\section{ACKNOWLEDGMENTS}

The work summarized in this article was supported by the following grants from the National Institute of Health: AG07232, AG15473, AG09029, AG07702, AG15294, RR00645, AG17761, AG12101, MH55735, MH35636, MH55646, P50 AG08702, AG08051, AG02615, AG07232, RR006458.

The work was also supported by the Alzheimer's Association, the Blanchett Hooker Rockefeller Foundation, Charles S. Robertson Gift from the Banbury Fund, the Canadian Institutes of Health Research, the Howard Hughes Medical Institute, the Canadian Institutes of Health Research-Japan Science and Technology Trust, the Alzheimer Society of Ontario, the Canada Foundation for Innovation, the Ontario Research and Development Challenge Fund, the Ontario Mental Health Foundation, Genome Canada and the Alzheimer Society of Canada (PSH).

Authors' disclosures available online (http://www.jalz.com/disclosures/view.php?id=1446).

\section{REFERENCES}

[1] Scarmeas N, Stern Y, Tang MX, Mayeux R, Luchsinger JA (2006) Mediterranean diet and risk for Alzheimer's disease. Ann Neurol 59, 912-921.

[2] Scarmeas N, Stern Y, Mayeux R, Manly JJ, Schupf N, Luchsinger JA (2009) Mediterranean diet and mild cognitive impairment. Arch Neurol 66, 216-225.

[3] Scarmeas N, Stern Y, Mayeux R, Luchsinger JA (2006) Mediterranean diet, Alzheimer disease, and vascular mediation. Arch Neurol 63, 1709-1717.

[4] Scarmeas N, Luchsinger JA, Schupf N, Brickman AM, Cosentino S, Tang MX, Stern Y (2009) Physical activity, diet, and risk of Alzheimer disease. JAMA 302, 627-637. 
[5] Scarmeas N, Albert SM, Manly JJ, Stern Y (2006) Education and rates of cognitive decline in incident Alzheimer's disease. J Neurol Neurosurg Psychiatry 77, 308-316.

[6] Helzner EP, Luchsinger JA, Scarmeas N, Cosentino S, Brickman AM, Glymour MM, Stern Y (2009) Contribution of vascular risk factors to the progression in Alzheimer disease. Arch Neurol 66, 343-348.

[7] Tabert MH, Manly JJ, Liu X, Pelton GH, Rosenblum S, Jacobs M, Zamora D, Goodkind M, Bell K, Stern Y, Devanand DP (2006) Neuropsychological prediction of conversion to Alzheimer disease in patients with mild cognitive impairment. Arch Gen Psychiatry 63, 916-924.

[8] Stern Y (2006) Cognitive reserve and Alzheimer disease. Alzheimer Dis Assoc Disord 20, S69-S74.

[9] Devanand DP, Pradhaban G, Liu X, Khandji A, De Santi S, Segal S, Rusinek H, Pelton GH, Honig LS, Mayeux R, Stern Y, Tabert MH, de Leon MJ (2007) Hippocampal and entorhinal atrophy in mild cognitive impairment: Prediction of Alzheimer disease. Neurology 68, 828-836.

[10] Lee JH, Cheng R, Schupf N, Manly J, Lantigua R, Stern Y, Rogaeva E, Wakutani Y, Farrer L, St George-Hyslop P, Mayeux R (2007) The association between genetic variants in SORL1 and Alzheimer disease in an urban, multiethnic, community-based cohort. Arch Neurol 64, 501-506.

[11] Amatniek JC, Hauser WA, DelCastillo-Castaneda C, Jacobs DM, Marder K, Bell K, Albert M, Brandt J, Stern Y (2006) Incidence and predictors of seizures in patients with Alzheimer's disease. Epilepsia 47, 867-872.

[12] Scarmeas N, Luchsinger JA, Mayeux R, Stern Y (2007) Mediterranean diet and Alzheimer disease mortality. Neurology 69, 1084-1093.

[13] Tang M-X, Maestre G, Tsai W-Y (1996) Relative risk of Alzheimer's disease and age-at-onset base of APOE genotypes among elderly among elderly African Americans, Caucasians and Hispanics in New York City. Am J Hum Genet 58, 554-574.

[14] Reitz C, Tang MX, Schupf N, Manly JJ, Mayeux R, Luchsinger JA (2010) Association of higher levels of highdensity lipoprotein cholesterol in elderly individuals and lower risk of late-onset Alzheimer disease. Arch Neurol 67, 1491-1497.
[15] Scarmeas N, Luchsinger JA, Stern Y, Gu Y, He J, Decarli C, Brown T, Brickman AM (2011) Mediterranean diet and magnetic resonance imaging-assessed cerebrovascular disease. Ann Neurol 69, 257-268.

[16] (2010) NIH Consensus Development Conference Statement on Preventing Alzheimer's Disease and Cognitive Decline. NIH Consensus and State-of-the-Art Statements, 27, http://consensus.nih.gov/2010/docs/alz/ALZ_Final_Statement. pdf.

[17] Lee JH, Cheng R, Honig LS, Vonsattel JP, Clark L, Mayeux R (2008) Association between genetic variants in SORL1 and autopsy-confirmed Alzheimer disease. Neurology 70, 887889.

[18] Meng Y, Lee JH, Cheng R, St George-Hyslop P, Mayeux R, Farrer LA (2007) Association between SORL1 and Alzheimer's disease in a genome-wide study. Neuroreport 18, 1761-1764.

[19] Reitz C, Cheng R, Rogaeva E, Lee JH, Tokuhiro S, Zou F, Bettens K, Sleegers K, Tan EK, Kimura R, Shibata N, Arai H, Kamboh MI, Prince JA, Maier W, Riemenschneider M, Owen M, Harold D, Hollingworth P, Cellini E, Sorbi S, Nacmias B, Takeda M, Pericak-Vance MA, Haines JL, Younkin S, Williams J, van Broeckhoven C, Farrer LA, St George-Hyslop PH, Mayeux R (2011) Meta-analysis of the association between variants in SORL1 and Alzheimer disease. Arch Neurol 68, 99-106.

[20] Rogaeva E, Meng Y, Lee JH, Gu Y, Kawarai T, Zou F, Katayama T, Baldwin CT, Cheng R, Hasegawa H, Chen F, Shibata N, Lunetta KL, Pardossi-Piquard R, Bohm C, Wakutani Y, Cupples LA, Cuenco KT, Green RC, Pinessi L, Rainero I, Sorbi S, Bruni A, Duara R, Friedland RP, Inzelberg R, Hampe W, Bujo H, Song YQ, Andersen OM, Willnow TE, Graff-Radford N, Petersen RC, Dickson D, Der SD, Fraser PE, Schmitt-Ulms G, Younkin S, Mayeux R, Farrer LA, St George-Hyslop P (2007) The neuronal sortilin-related receptor SORL1 is genetically associated with Alzheimer disease. Nat Genet 39, 168-177.

[21] Lee JH, Shibata N, Cheng R, Mayeux R (2008) Possible association between SORL1 and Alzheimer disease? Reanalysing the data of Shibata et al. Dement Geriatr Cogn Disord 26, 482 . 